\title{
Management of bone metastases in renal cell carcinoma: bone-targeted treatments, systemic therapies, and radiotherapy
}

\author{
André Mansinho ${ }^{1,2}$, Priscila Nejo ${ }^{3}$, Tito Leitão ${ }^{2,4}$, Sandra Casimiro ${ }^{1,2}$, Luís Costa ${ }^{1,2}$ \\ 'Serviço de Oncologia Médica, Centro Hospitalar Universitário Lisboa Norte, Hospital de Santa Maria, Lisboa 1649-035, Portugal. \\ ${ }^{2}$ Luis Costa Laboratory, Instituto de Medicina Molecular, Faculdade de Medicina da Universidade de Lisboa, Lisboa 1649-035, \\ Portugal. \\ ${ }^{3}$ Instituto Português de Oncologia Lisboa Francisco Gentil, Lisboa 1649-035, Portugal. \\ ${ }^{4}$ Urology Department, Centro Hospitalar Universitário Lisboa Norte, Hospital de Santa Maria, Lisboa 1649-035, Portugal.
}

Correspondence to: Prof. Luís Costa, Serviço de Oncologia Médica, Centro Hospitalar Universitário Lisboa Norte, Hospital de Santa Maria, Av. Prof Egas Moniz, Lisboa 1649-035, Portugal. E-mail: luiscostaoncology@gmail.com

How to cite this article: Mansinho A, Nejo P, Leitão T, Casimiro S, Costa L. Management of bone metastases in renal cell carcinoma: bone-targeted treatments, systemic therapies, and radiotherapy. J Cancer Metastasis Treat 2021;7:44. https://dx.doi.org/10.20517/2394-4722.2021.88

Received: 2 Apr 2021 First Decision: 10 May 2021 Revised: 25 May 2021 Accepted: 2 Jun 2021 First online: 6 Jun 2021

Academic Editor: Hendrik Van Poppel Copy Editor: Yue-Yue Zhang Production Editor: Yue-Yue Zhang

\begin{abstract}
Metastatic renal cell carcinoma (mRCC) presents with bone metastases in around 20\%-30\% of patients enrolled in the most recent first-line clinical trials. Emergence of several new agents in first line, in both monotherapy and combination, has significantly improved patient outcomes. However, the activity of such agents on bone metastases is unclear and management of these patients is complex, due to potential complications that can significantly impair quality of life. This review addresses mRCC diagnosis and monitoring and summarizes the current evidence on systemic therapy, ablative therapies such as stereotactic ablative radiotherapy and surgery, and supportive therapy with bone-targeting agents for these patients, with the goal of improving their outcomes.
\end{abstract}

Keywords: Bone metastases, renal cell carcinoma, bone targeted treatments, radiotherapy, systemic therapy

\section{INTRODUCTION}

Renal cell carcinoma (RCC) is a heterogeneous disease, with clear cell RCC (ccRCC) representing about 
$75 \%$ of all cases. ccRCC is characterized by frequent alterations in the Von Hippel-Lindau (VHL) gene, upregulation of VEGF, activation of the phosphoinositol-3-kinase-Akt-mTOR pathway, and increased migration ability and angiogenesis ${ }^{[1]}$. Among the non-clear cell RCC, papillary RCC is the most prevalent (10\%-15\%), and characterized by MET alterations (Type I) or a panoply of molecular alterations (Type II) ${ }^{[2]}$.

Evidence suggests that metastasis in RCC is mostly driven by hematogenous dispersion of tumor-derived microvesicles, which carry CD105-positive RCC cancer stem cells and pro-angiogenic mRNAs ${ }^{[3]}$. In VHLmutated ccRCC, HIF-regulated CUB-domain-containing protein and MUC1 are considered to be metastasis drivers, by increasing migration ${ }^{[4,5]}$. As in other cancers, the chemokine receptor CXCR4 is also upregulated in ccRCC and associated with increased metastatic ability ${ }^{[6]}$.

Bone can be affected by metastatic disease in virtually any cancer. One pivotal discovery in cancer research was breast cancer cell tropism to bone, which led to the "seed and soil hypothesis" ${ }^{[7]}$. Bone metastases (BM), also common among patients with RCC, are present in up to one third of patients with metastatic disease [Table 1] $]^{[8]}$.

BM can lead to significant morbidity in cancer patients, with progressive autonomy loss and impaired quality of life (QoL) ${ }^{[14]}$. In metastatic RCC (mRCC), BM are typically osteolytic, compromising bone integrity and eventually leading to skeletal-related events (SREs), including pathologic fractures, impending fracture requiring surgical intervention, bone pain requiring radiotherapy, spinal cord compression, and hypercalcemia ${ }^{[15]}$. In addition to these devastating complications, BM have a negative impact on the progression-free survival (PFS) and overall survival (OS) of mRCC patients treated with systemic therapies compared to patients without $\mathrm{BM}^{[16]}$. Moreover, development of $\mathrm{BM}$ at first-line treatment start resulted in significantly shorter survival compared with later points in time. Despite several studies reporting that BM are associated with higher risk of morbidity and shorter survival in mRCC patients, heterogeneity of study populations has been a critical drawback ${ }^{[17]}$. Median OS after diagnosis of RCC BM ranges from 12 to 28 months ${ }^{[18]}$. Suggested reasons for poor survival outcomes in BM patients include interactions between cancer cells and tumor microenvironment, particularly bone microenvironment, with subsequent bone destruction and rapid tumor growth ${ }^{[19]}$. A retrospective analysis of 94 patients with RCC and BM suggested five prognosis-predictive risk factors in this setting: sarcomatoid differentiation of the primary tumor $(P=$ $0.001)$, spinal involvement $(P=0.003)$, extraosseous metastases $(P=0.021)$, increased alkaline phosphatase levels $(>1.5$ times the upper limit of normal; $P=0.0003)$, and increased $C$-reactive protein levels $(>0.3 \mathrm{mg} / \mathrm{dL}, P=0.018)^{[20]}$.

BM are associated with substantial morbidity, mortality, QoL deterioration, and economic burden. A recent propensity score matching analysis revealed that the presence of BM negatively affects OS outcomes in mRCC patients treated with first-line tyrosine kinase inhibitors (TKI), particularly in the International Metastatic Renal Cell Carcinoma Database (IMDC) intermediate-risk group ${ }^{[21]}$. Treatment toxicity and disease progression are expected to have a negative impact on QoL while increasing costs, due to the associated need for additional treatment, hospitalizations, and other management requirements. Therefore, correctly identifying patients with BM for preemptive treatment is of utmost importance for minimizing morbidity and improving patient outcomes and QoL. This review addresses RCC BM pathophysiology, as well as diagnosis and treatment in the mRCC setting.

\section{BONE METASTASES PATHOPHYSIOLOGY}

The metastatic cascade is an intricate and complex process that culminates with cancer cell seeding and colonization at a distant site of the primary tumor ${ }^{[22]}$. Bone marrow is a preferential site for seeding of 
Table 1. BM incidence and outcomes in metastatic renal cell carcinoma first-line studies

\begin{tabular}{llll}
\hline Trial & \% of patients with BM & HR (95\%Cl) vs. sunitinib (PFS) & HR (95\%Cl) vs. sunitinib (OS) \\
\hline Checkmate-214 $^{[9]}$ & $20.0 \%$ & NR & $0.71(0.47-1.08)$ \\
${\text { Javelin Renal } 101^{[10]}}^{\text {N }}$ & NR & NR & NR \\
KEYNOTE-426 $^{[11]}$ & $23.8 \%$ & NR & NR \\
CHECKMATE-9ER $^{[12]}$ & $24.1 \%$ & $0.34(0.22-0.55)$ & $0.54(0.32-0.92)$ \\
CLEAR $^{[13]}$ & $23.9 \%$ & NR & NR \\
\hline
\end{tabular}

BM: Bone metastases; HR: hazard ratio; NR: not reported; OS: overall survival; PFS: progression-free survival.

cancer cells expressing C-X-C Motif Chemokine Receptor 4 and 7 (CXCR4 and CXCR7), due to the stromal cell-derived factor 1, also known as C-X-C Motif Chemokine 12 (CXCL12), chemotactic effect ${ }^{[23]}$. After seeding, interaction with bone microenvironment is crucial for colonization, and, as cancer cells adapt and grow, they ultimately become able to exploit and manipulate the stroma, in the so-called "vicious cycle of bone metastases" by Mundy and Guise ${ }^{[24]}$.

The balance between bone resorption and formation is well preserved in healthy bone, whereas it is disrupted and shifted towards bone resorption in BM. In physiological conditions, the triad of receptor activator of nuclear factor $\mathrm{kB}$ ligand (RANKL), RANK, and osteoprotegerin (OPG) assures homeostasis ${ }^{[25]}$. RANK is a transmembrane receptor that is present on the surface of osteoclast precursor cells and can be activated by its ligand RANKL, produced by osteoblasts, osteocytes, and bone marrow stromal cells. RANK activation by its ligand regulates osteoclast activity, survival, and differentiation ${ }^{[26]}$. The RANKL soluble decoy OPG, secreted by mature osteoblasts and stromal cells, can block RANK activation and prevent bone resorption. In pathological conditions, such as those of osteolytic metastases, tumor-derived osteoclastogenic factors - such as interleukin 1 (IL-1), IL-6, parathyroid hormone-related protein (PTHrP), prostaglandin E2, colony-stimulating factor 1, and tumor necrosis factor- $\alpha$ - elicit increased bone resorption $^{[27]}$. RANKL expression is upregulated by increased PTHrP and IL-11, leading to OPG downregulation and activated osteclastogenesis. Therefore, mitogenic factors are further released from bone matrix, further feeding the "vicious cycle" of tumor growth and bone resorption.

In mRCC with $\mathrm{BM}$, the hepatocyte growth factor/c-Met pathway has an important role in disease pathophysiology, as recently reviewed ${ }^{[28]}$. c-Met is abnormally expressed in different tumors, including $\mathrm{RCC}^{[29-31]}$. In a retrospective analysis of nephrectomy specimens from $17 \mathrm{mRCC}$ patients, high $c$-Met expression at primary sites was identified in $47 \%$ of nephrectomy and $86 \%$ of bone specimen ${ }^{[32]}$. Pre-clinical data suggest that c-Met contributes to cancer stem cell (CSC) maintenance and CSCs-induced BM in mRCC, but its mechanism is still unknown.

\section{DIAGNOSIS}

As previously stated, BM early diagnosis and preemptive treatment are key for preventing SREs and reducing morbidity and QoL deterioration.

Conventional radiography performed in two projections is usually the first exam when patients have BMsuggestive symptoms, as it can be useful to retrieve information on size and location, as well as fracture risk, when performed by an experienced orthopedic surgeon. Additionally, this exam [Figure 1] enables classifying whether the tumor is osteolytic (bone-destroying), osteoblastic (bone-building), or mixed. Although quick and easy to obtain, as well as inexpensive, it needs to be further complemented with other methods, as it is not suitable for use as a screening test, due to its low sensitivity. 


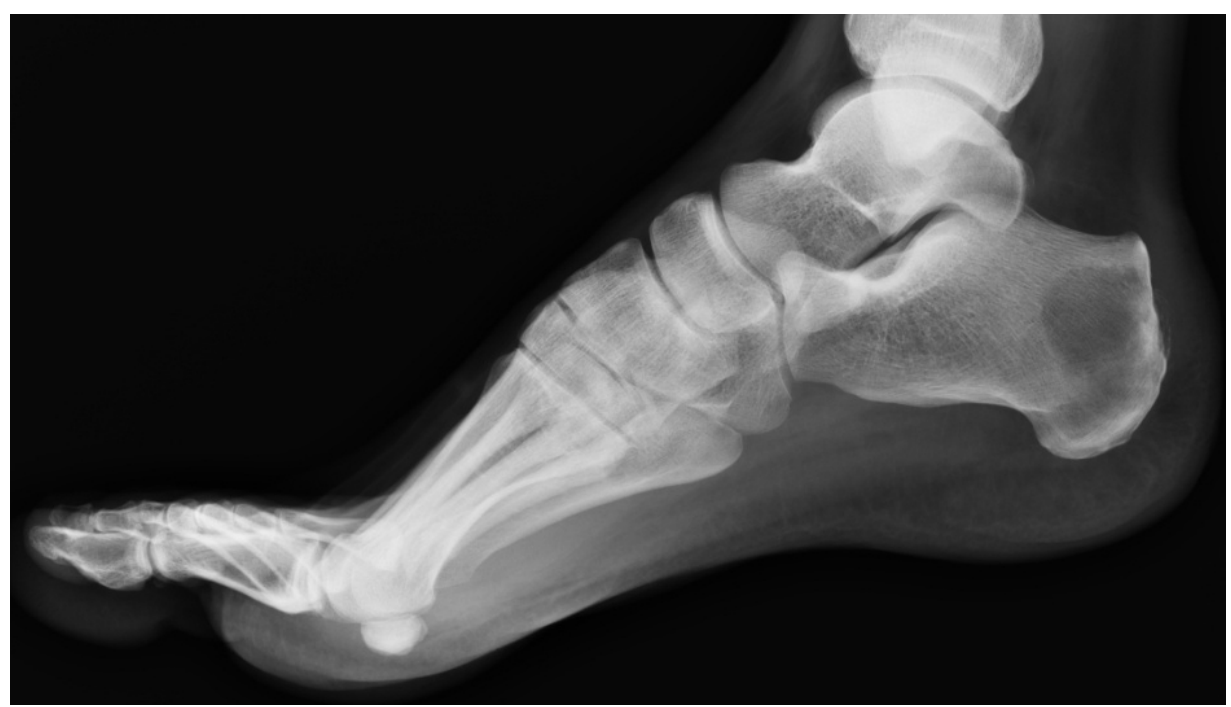

Figure 1. Right calcaneus osteolytic bone metastasis from mRCC (conventional radiography).

Computed tomography (CT) is another complementary imaging technique that can be used to diagnose and study BM, as it allows establishing the structure and volume of metastatic lesion, magnitude of cortical bone destruction, and presence of periosteal reactions, as well as assess fracture risk ${ }^{[33]}$. It can be extremely sensitive for osteolytic and osteoblastic bone lesions involving cortical bone, but not for tumors restricted to the marrow space, being of limited use as a screening test ${ }^{[34]}$.

Skeletal scintigraphy with labeled phosphonates enables bone metabolism visualization. The classical screening imaging method is Technetium-99m bone scintigraphy, which enables depicting the entire skeleton and identifying osteoblastic activity, by detecting hot spots in bone metabolism. Therefore, it is very sensitive for BM with marked reactive bone hypermetabolism but relatively insensitive for tumors with non-reactive osteolysis or isolated bone-marrow infiltration (such as $\mathrm{mRCC}$ ) ${ }^{[35,36]}$. One additional issue is that bone matrix regeneration induced by BM treatment leads to metabolic activation, which can be read as increased activity in the bone scan (flare phenomenon).

Positron emission tomography combined with CT with $18 \mathrm{~F}$-fluorodeoxyglucose (PET-CT-FDG) and whole-body magnetic resonance imaging (MRI) have increased sensitivity for bone lesions compared to bone scintigraphy, with the latter excelling at renal BM detection [Figure 2]. MRI is based on cell proton content detection, as cancer cells comprise more water molecules than bone marrow or cortical bone ones $^{[37]}$. Given its high soft tissue contrast and spatial resolution, MRI can detect metastases with $91 \%$ sensitivity and $95 \%$ specificity very early in time, before bone structure changes can be detected in CT scan $^{[38]}$. PET-CT-FDG uses 18 F-fluorodeoxyglucose marker, which enables identifying cells with increased glucose uptake, such as tumor cells. It can be combined with CT scan data, retrieving high-resolution images with metabolic information ${ }^{[39]}$. As BM are highly metabolic, they can be detected with high sensitivity and specificity. Bone lesions associated with RCC are typically osteolytic, so bone scintigraphy with Tc-99m has a limited sensitivity when compared, for instance, with FDG PET/CT. Wu et al. ${ }^{[00]}$ compared FDG PET with bone scan in patients with RCC and suspected bone metastases confirmed by histopathology. PET-FDG had 100\% diagnostic sensitivity and accuracy, while bone scintigraphy had 77.5\% and 59.6\%, respectively. Besides being two excellent diagnostic methods, PET-CT-FDG and CT scan are also better at assessing therapy response in bone lesions ${ }^{[41]}$, however with the drawbacks of availability and price. 


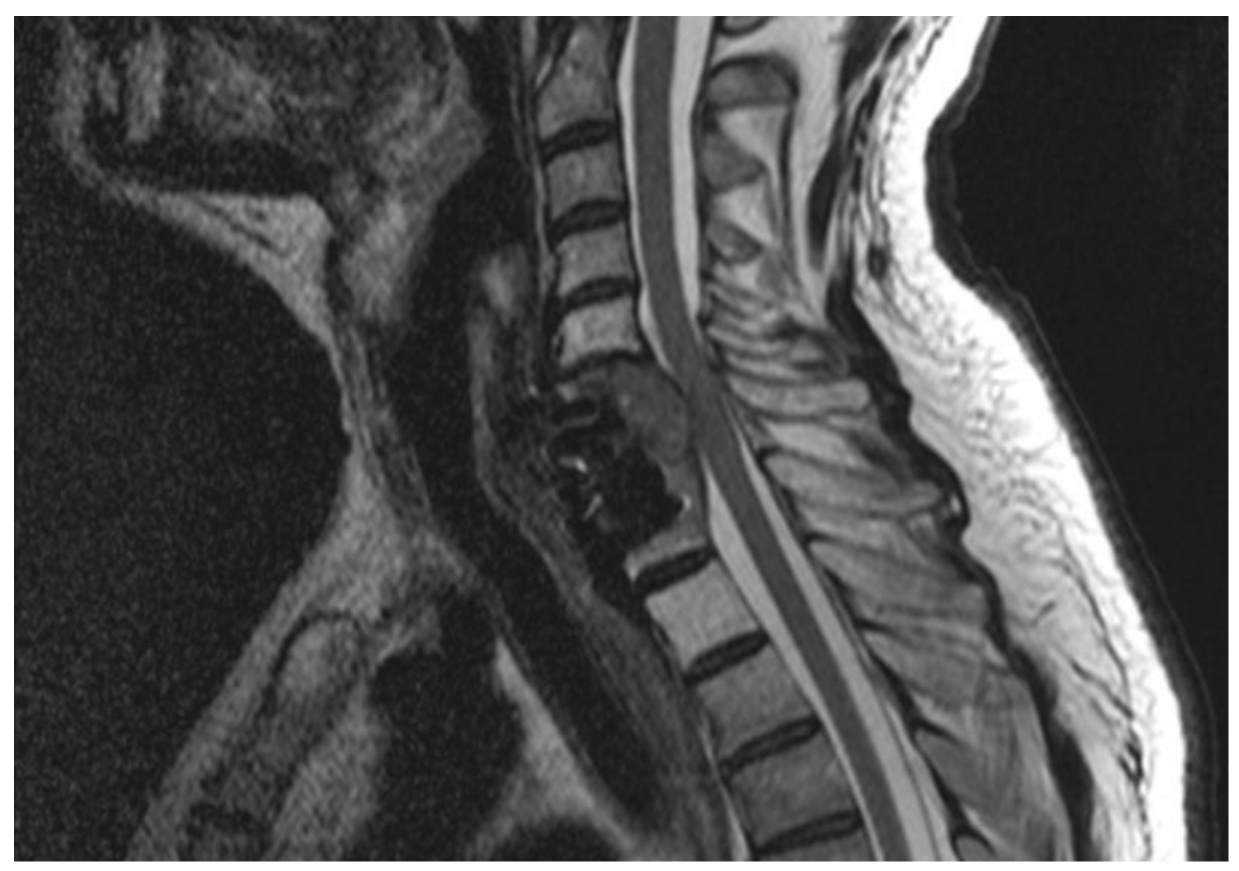

Figure 2. Osteolytic lesion of $\mathrm{mRCC}$ with soft tissue component and spinal cord compression on the 6th and 7th cervical vertebrae (MRI).

\section{BONE METASTASES TREATMENT}

Bone metastasis in mRCC can be targeted by several classes of agents or local ablative therapies, in both monotherapy and combination [Table 2].

\section{Bone-targeted agents}

According to radiographic density, BMs can be osteoblastic, osteolytic, or mixed. However, as osteoclastic activity increase is common to all BM types, targeting osteoclasts has been one of the main treatment approaches in this setting ${ }^{[42]}$. Bone-targeted agents (BTAs), such as bisphosphonates (BPs) and denosumab, are used to prevent SREs, and recent evidence suggests that BPs, such as zoledronic acid, can be adjunctively used with systemic therapy to decrease SREs in patients with mRCC and BM.

BPs have the particularity of high affinity for calcium ions and become attached to hydroxyapatite binding sites on the bone surface, especially when undergoing active resorption. BPs are internalized by active osteoclasts, inhibiting their function ${ }^{[43]}$. Pamidronate and zoledronic acid are European Medical Agency and Food and Drug Administration - approved BPs for prevention of SREs in patients with solid tumors and BM.

Different types of BPs are currently available. First-generation (non-nitrogenous) BPs include clodronate, first studied in 1987 in a small trial with 34 breast cancer patients with osteolytic BM. The study showed that a $1.6 \mathrm{~g} /$ day dose of clodronate for 12 months reduced bone pain, development of new osteolytic foci, and $\mathrm{BM}$ extension and prevented severe hypercalcemia ${ }^{[4]]}$. This was further validated some years later, in a larger, double-blind trial that showed a drastic SRE reduction ${ }^{[45]}$.

Second-generation nitrogenous BPs were subsequently developed. Pamidronate at the dose of $90 \mathrm{mg}$ intravenous monthly for 12 cycles was evaluated in a double-blind randomized trial in breast cancer 
Table 2. Treatments for bone metastasis in mRCC

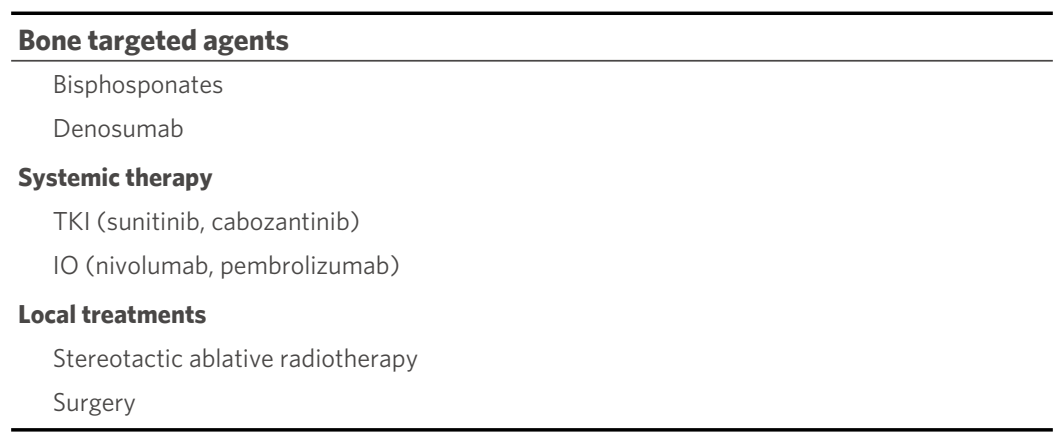

patients with BM under active systemic therapy. In this trial, significant SRE and pain reduction was observed $^{[46,47]}$.

More recently, the third-generation nitrogenous BP zoledronic acid was compared with pamidronate, also in the breast cancer with BM setting, with no significant differences ${ }^{[48]}$. Zoledronic acid was further compared with ibandronate in the ZICE trial, a positive non-inferiority study that placed ibandronate as an alternative for patients for whom frequent hospital visits are not ideal ${ }^{[49]}$.

Data on BP efficacy in solid tumors other than breast and prostate are scarce. Zoledronic acid was evaluated in a placebo-controlled trial of 773 patients with other tumors and BM and shown to reduce SRE incidence and increase time to first $\mathrm{SRE}^{[50]}$.

In the mRCC setting, a phase II trial randomized 30 patients in a 1:1 ratio to receive everolimus alone or everolimus and zoledronic acid ${ }^{[51]}$. Despite everolimus no longer being the standard mRCC treatment, zoledronate may have an important role in delaying time to SREs. This was supported by a recent metaanalysis showing that zoledronic acid reduced SRE risk by $68 \%$ (HR $=0.32,95 \% \mathrm{CI}$ : 0.19-0.55) compared with placebo or no zoledronic acid ${ }^{[52]}$.

The BTA denosumab, a fully humanized anti-RANKL monoclonal antibody, emerged from research on key bone remodeling mediators ${ }^{[53]}$. Denosumab can be an alternative for patients with renal disfunction or other conditions, limiting the use of zoledronic acid. In a pivotal phase III trial, denosumab was non-inferior to zoledronic acid in delaying time to first SRE in various advanced tumors $(\mathrm{HR}=0.84,95 \% \mathrm{CI}: 0.71-0.98)^{[54]}$. Additionally, a meta-analysis including 5723 patients from three trials found that denosumab significantly improved time to first SRE by a median of 8.21 months and reduced the risk of a first SRE by $17 \%$ compared with zoledronic acid $(\mathrm{HR}=0.83,95 \% \mathrm{CI} \text { : 0.76-0.90, } P<0.001)^{[55]}$. Data regarding use of denosumab in urological cancers were also presented at ASCO $2013^{[56]}$, in a study including urological patients of the 20050244 trial and prostate cancer patients of the 2005103 trial. In total, $85 \mathrm{mRCC}$ patients were randomized to zoledronic acid and 70 to denosumab in the 20050244 trial, which reported a trend in lowering the time to occurrence of first on-study SRE with denosumab (HR = 0.71, 95\%CI: 0.43-1.17).

It should be noted that there is an added risk of osteonecrosis of the jaw (ONJ) with cumulative exposure to denosumab and $\mathrm{BPs}^{[57]}$. Therefore, physicians should consider a full dental examination in patients planned to start these agents, and any necessary oral health intervention should be done before starting therapy. Additionally, frequent clinical assessment of the oral mucosa should be a priority. Particular attention should be given when administering BTAs concomitantly with other therapies, as anti-angiogenic TKIs 
further increase ONJ risk when combined with those agents. In a series of 41 patients treated with denosumab and an anti-angiogenic TKI, ONJ incidence was 17\% (contrasting with pivotal denosumab trials $)^{[58]}$. Additionally, a multicenter retrospective study including 44 patients mostly under anti-angiogenic TKIs and BTAs reported an unexpectedly high number of ONJ cases, which contrasts with literature data and suggests that the frequency of ONJ in RCC patients may be largely underestimated ${ }^{[5]}$.

In addition to bisphosphonates, radioisotopes have also been investigated in this setting. Radium-223 acts as a calcimimetic, and therefore it has a high affinity to skeletal lesions that typically have an increased bone turnover. Being an alpha-emitting agent, radium-223 can prevent the progression of bone metastasis by killing cancer cells and breaking the vicious cycle of bone metastasis, stabilizing the tumoral microenvironment. In a study by McKay et al. ${ }^{[00]}$, the addition of radium-223 to VEGF-targeted therapy in patients with $\mathrm{mRCC}$ and bone metastases was studied. This association produced a significant decrease in the serum levels of five bone turnover markers, with no limiting toxicity. These data suggest that radium223 associated with VEGF-targeted therapy is safe and might be useful in treating mRCC patients, although we need clinical trial data to see if this approach reduces the rate and incidence of SREs in these patient ${ }^{[60]}$. The RadiCal trial is a phase II randomized protocol that is currently investigating this (SSE as a primary endpoint), by comparing cabozantinib with radium-223 in combination with cabozantinib (NCT04071223).

\section{Systemic therapy}

Systemic treatment options for patients with mRCC include TKIs targeting the vascular endothelial growth factor receptor, the mammalian target of rapamycin (mTOR), and other pathways ${ }^{[6]}$. Additionally, monoclonal antibodies, such as the anti-VEGF bevacizumab, and immune checkpoint inhibitors, such as pembrolizumab, nivolumab, and ipilimumab, have yielded positive results, both alone and in combination $^{[62,63]}$.

Data regarding BM and systemic therapy is also scarce. Preclinical evidence suggests that sunitinib can inhibit osteoclastic activity ${ }^{[64]}$. In a study by Shinya et al. ${ }^{[64]}$, the number of osteoclasts in mice treated with sunitinib was significantly lower than in the controls, suggesting sunitinib may inhibit osteoclast maturation. Additionally, a decline in serum and urine levels of amino-terminal telopeptide was seen in patients with mRCC during the first four weeks of sunitinib treatment, suggesting that it might have significant activity in patients with RCC and bone metastasis ${ }^{[65]}$.

Although there are no prospective clinical data supporting this, two retrospective analyses found that sunitinib prolongs OS compared to historical controls ${ }^{[6]}$ and decreases development and time to new bone lesions compared to sorafenib ${ }^{[67]}$.

Cabozantinib is an approved treatment for mRCC, in both first and second line, and has been studied in the subgroup of BM patients, in the METEOR trial. In this study, the median survival of patients with BM was 20 months in the cabozantinib arm and 12 months in the everolimus arm in the second- or higher-line setting ${ }^{[6,69]}$. In a preclinical study, it was shown that doses of cabozantinib below the threshold of cytotoxicity inhibit osteoclast differentiation and bone resorption activity. Additionally, cabozantinib downregulated the expression of osteoclast marker genes, and direct cell-to-cell contact between cabozantinib pre-treated osteoblasts and untreated osteoclasts confirmed the indirect anti-resorptive effect of cabozantinib ${ }^{[70]}$. Moreover, recent data from a subgroup analysis of the Checkmate-9ER trial evaluating nivolumab plus cabozantinib confirm an OS and PFS benefit of the combination in BM patients ${ }^{[12]}$. A favorable OS trend was also observed in a subgroup analysis of the Checkmate-214 trial $^{[0]}$, comparing nivolumab plus ipilimumab with sunitinib, and in the Checkmate- 025 trial $^{[71]}$, comparing nivolumab with 
everolimus in second or further lines of treatment.

There is an ongoing phase II trial investigating the combined use of pembrolizumab and denosumab in clear-cell mRCC that may also shed some light on this treatment option ${ }^{[72]}$.

\section{Stereotactic ablative radiation therapy}

RCC is refractory to conventional radiation therapy but responds to higher doses per fraction. In 2019, the National Comprehensive Cancer Network guidelines included stereotactic ablative radiotherapy (SBRT) in the treatment of recurrent and metastatic $\mathrm{RCC}^{[73]}$. Because tumor cell survival and proliferation directly rely on blood supply, SBRT has been shown to have a direct effect on tumor vasculature.

The use of SBRT in metastatic bone lesions has also been investigated. Investigators from the Memorial Sloan Kettering Cancer Center compared the use of single-fraction (18-24 Gy) or hypofractioned (3-5 fractions to 20-30 Gy), by assessing tumor control rates in 105 patients with extracranial mRCC. Local control rates were best when using high single ( $24 \mathrm{~Gy})$ compared with low single $(<24 \mathrm{~Gy})$ dose or hypofractionated regimens, with three-year local PFS of $88 \%, 21 \%$, and $17 \%$, respectively ${ }^{[74]}$. Jhaveri et al. ${ }^{[75]}$ investigated pain relief in RCC BM patients treated with SBRT and reported quicker and more durable pain control in those treated with BED of $>85$ Gy compared with $<85$ Gy, with $78 \%$ and $32 \%$ of patients, respectively, showing symptom control at 10 weeks. A study from the M.D. Anderson Center reported oneyear spine tumor PFS of $82.1 \%$ with SBRT, with approximately half of all patients free of symptoms at one year ${ }^{[76]}$.

With additional targeted therapies, the role of systemic therapy in RCC continues to improve, increasing patients' survival and QoL. SBRT will play a valuable role in providing not only high local control rates but also prolonged symptomatic control from months to years.

\section{Surgery}

In mRCC, surgical metastasectomy (SM) is mostly performed for patients with pulmonary lesions, which represent the most frequent site for RCC metastases ${ }^{[77]}$. A systematic review of eight studies assessed the role of local therapy in mRCC and reported a longer OS and cancer-specific survival (CSS) in patients undergoing complete metastasectomy than in those undergoing either incomplete or no metastasectomy [40.8 months, interquartile range (IQR): 31.6-48.0 vs. 14.8 months, IQR: 13.3-21.0, respectively]. Patients with pancreatic, liver, and lung lesions derived the greatest advantage from complete metastasectomy when compared to incomplete or no metastasectomy ${ }^{[77]}$.

Generally, BM are more resistant to systemic therapy and radiotherapy when compared to other metastases sites, and, additionally, they are highly destructive. The role of metastasectomy in mRCC with BM was recently reviewed in a retrospective study with 114 patients. Single BM was seen in 68 (59.6\%) patients, whereas 46 (40.4\%) had multiple (2-5) BM. BM were located in axial bones (spine, skull, and ribs) in 47 $(41.2 \%)$ patients, in the appendicular skeleton (extremities, pelvis, clavicle, and scapula) in 20 (17.5\%), in multiple sites in $33(28.9 \%)$, and in unknown exact location in $14(12.3 \%)^{[78]}$. BM excisional surgery, particularly in the spine, is a procedure which is technically very demanding, even for specialized orthopedic and spine surgeons. Bone metastases from mRCC are destructive and hypervascular [Table 3], and, in the majority of cases, reconstruction is required after tumor resection to support the operated lesion against the load. A case series of 36 consecutive patients concluded that, for selected patients, complete spinal resection of spinal metastases can potentially prolong survival, with a median CSS of 130 months. In this series, the presence of liver metastases was a potential drawback to this strategy, being associated with 
Table 3. Typical characteristics of BM in renal cell carcinoma

\begin{tabular}{l}
\hline Clinical and pathologic features of renal cell carcinoma BM \\
\hline Mostly osteolytic ${ }^{[15]}$ \\
- High c-MET expression ${ }^{[29-31]}$ \\
- Radioresistant [require high biologically effective dose (BED) $]^{[76]}$ \\
- Highly vascularized and destructive ${ }^{[80]}$ \\
\hline
\end{tabular}

short-term survival after spinal metastasectomy ${ }^{[79]}$.

In many cases, treatment goals for patients with BM do not include complete SM, but instead palliative surgery combined with non-surgical treatment to preserve or restore neurological function and improve pain control ${ }^{[80]}$. Spinal metastases can represent a particularly difficult case with regards to symptoms and treatment, as neurological pain is often added to nociceptive pain, and neurological impairment can be observed. Due to close contact with the spinal cord, spinal BM treatment is challenging and requires a multidisciplinary approach ${ }^{[81]}$.

\section{CONCLUSION}

BM and SREs increase economic burden and decrease QoL, ultimately increasing morbidity throughout the metastatic disease course. Additionally, the overall prognosis of these patient is poor, compared with patients without BM. Advances in systemic and ablative therapy have improved these patients' outcomes in recent years. BM in patients with RCC may have a special sensitivity to drugs targeting c-Met, and administration of BTAs can further improve time to SREs and minimize QoL deterioration. Combining and sequencing all these resources can be complex, making multidisciplinary intervention of utmost importance to maximize patient outcomes and treatment.

\section{DECLARATIONS}

\section{Acknowledgments}

Joana Cavaco Silva is a scientific and biomedical consultant and a senior medical writer for the Medical Oncology Deparment of CHULN.

\section{Authors' contributions}

Contributed significantly and similarly to the conceptualization, writing and review of the article: Mansinho A, Nejo P, Leitão T, Casimiro S, Costa L

\section{Availability of data and materials}

Not applicable.

\section{Financial support and sponsorship}

None.

\section{Conflicts of interest}

Luís Costa has received research grants from Amgen, Bayer, Novartis and Roche, speaker honoraria from Amgen, Bayer, Janssen, Lilly and Roche, and is also a consultant for Amgen, Novartis and Servier. André Mansinho has received honoraria as consultant/speaker from Amgen, Astellas, Bayer, Bristol Myers-Squibb, Janssen, Merck-Serono, Merck Sharp \& Dohme, Novartis, OMPharma, Pfizer, Pierre Fabre, Roche, Servier, Travel/Logistics support from Amgen, Astellas, Bayer, Bristol Myers-Squibb, Janssen, Merck-Serono, Merck Sharp \& Dohme, Novartis, OMPharma, Pfizer, Pierre Fabre, Roche, Servier and Research funding from Bayer. 


\section{Ethical approval and consent to participate}

Not applicable.

\section{Consent for publication}

Not applicable.

\section{Copyright}

(c) The Author(s) 2021.

\section{REFERENCES}

1. Kim WY, Kaelin WG. Role of VHL gene mutation in human cancer. J Clin Oncol 2004;22:4991-5004. DOI PubMed

2. Gong J, Maia MC, Dizman N, Govindarajan A, Pal SK. Metastasis in renal cell carcinoma: biology and implications for therapy. Asian J Urol 2016;3:286-92. DOI PubMed PMC

3. Grange C, Tapparo M, Collino F, et al. Microvesicles released from human renal cancer stem cells stimulate angiogenesis and formation of lung premetastatic niche. Cancer Res 2011;71:5346-56. DOI PubMed

4. Razorenova OV, Finger EC, Colavitti R, et al. VHL loss in renal cell carcinoma leads to up-regulation of CUB domain-containing protein 1 to stimulate PKC \{delta\}-driven migration. Proc Natl Acad Sci U S A 2011;108:1931-6. DOI PubMed PMC

5. Aubert S, Fauquette V, Hémon B, et al. MUC1, a new hypoxia inducible factor target gene, is an actor in clear renal cell carcinoma tumor progression. Cancer Res 2009;69:5707-15. DOI PubMed

6. Struckmann K, Mertz K, Steu S, et al. pVHL co-ordinately regulates CXCR4/CXCL12 and MMP2/MMP9 expression in human clearcell renal cell carcinoma. J Pathol 2008;214:464-71. DOI PubMed

7. Paget S. The distribution of secondary growths in cancer of the breast. 1889. Cancer Metastasis Rev 1989;8:98-101. PubMed

8. Bianchi M, Sun M, Jeldres C, et al. Distribution of metastatic sites in renal cell carcinoma: a population-based analysis. Ann Oncol 2012;23:973-80. DOI PubMed

9. Choueiri TK, Powles T, Burotto M, et al; CheckMate 9ER Investigators. Nivolumab plus cabozantinib versus sunitinib for advanced renal-cell carcinoma. N Engl J Med 2021;384:829-41. DOI PubMed

10. Motzer RJ, Penkov K, Haanen J, et al. Avelumab plus axitinib versus sunitinib for advanced renal-cell carcinoma. $N$ Engl $J$ Med 2019;380:1103-15. DOI PubMed PMC

11. Rini BI, Plimack ER, Stus V, et al; KEYNOTE-426 Investigators. Pembrolizumab plus axitinib versus sunitinib for advanced renalcell carcinoma. N Engl J Med 2019;380:1116-27. DOI PubMed

12. Motzer RJ, Tannir NM, McDermott DF, et al; CheckMate 214 Investigators. Nivolumab plus Ipilimumab versus Sunitinib in advanced renal-cell carcinoma. N Engl J Med 2018;378:1277-90. DOI PubMed PMC

13. Motzer RJ, Alekseev B, Rha SY, et al. Lenvatinib plus pembrolizumab or everolimus for advanced renal cell carcinoma. $N$ Engl $J$ Med 2021;384:1289-300. DOI PubMed

14. Kinnane N. Burden of bone disease. Eur J Oncol Nurs 2007;11 Suppl 2:S28-31. DOI PubMed

15. Beuselinck B, Oudard S, Rixe O, et al. Negative impact of bone metastasis on outcome in clear-cell renal cell carcinoma treated with sunitinib. Ann Oncol 2011;22:794-800. DOI PubMed

16. Santoni M, Conti A, Procopio G, et al. Bone metastases in patients with metastatic renal cell carcinoma: are they always associated with poor prognosis? J Exp Clin Cancer Res 2015;34:10. DOI PubMed PMC

17. Yuasa T, Urakami S, Yamamoto S, et al. Treatment outcome and prognostic factors in renal cell cancer patients with bone metastasis. Clin Exp Metastasis 2011;28:405-11. DOI PubMed

18. Chen SC, Kuo PL. Bone metastases from renal cell carcinoma. Int J Mol Sci 2016;17:987.

19. Kume H, Kakutani S, Yamada Y, et al. Prognostic factors for renal cell carcinoma with bone metastasis: who are the long-term survivors? J Urol 2011;185:1611-4. DOI PubMed

20. Grünwald V, Eberhardt B, Bex A, et al. An interdisciplinary consensus on the management of bone metastases from renal cell carcinoma. Nat Rev Urol 2018;15:511-21. DOI PubMed PMC

21. Kang M, Choi J, Kim J, et al. Prognostic impact of bone metastasis on survival outcomes in patients with metastatic renal cell carcinoma treated by first line tyrosine kinase inhibitors: a propensity-score matching analysis. J Cancer 2020;11:7202-8. DOI PubMed PMC

22. Steeg PS. Tumor metastasis: mechanistic insights and clinical challenges. Nat Med 2006;12:895-904. DOI PubMed

23. Wang J, Shiozawa Y, Wang J, et al. The role of CXCR7/RDC1 as a chemokine receptor for CXCL12/SDF-1 in prostate cancer. J Biol Chem 2008;283:4283-94. DOI PubMed

24. Weilbaecher KN, Guise TA, McCauley LK. Cancer to bone: a fatal attraction. Nat Rev Cancer 2011;11:411-25. DOI PubMed PMC

25. Trouvin AP, Goëb V. Receptor activator of nuclear factor- $\kappa \mathrm{B}$ ligand and osteoprotegerin: maintaining the balance to prevent bone loss. Clin Interv Aging 2010;5:345-54. DOI PubMed PMC

26. Dougall WC, Glaccum M, Charrier K, et al. RANK is essential for osteoclast and lymph node development. Genes Dev 1999;13:241224. DOI PubMed PMC

27. Casimiro S, Ferreira AR, Mansinho A, Alho I, Costa L. Molecular mechanisms of bone metastasis: which targets came from the bench to the bedside? Int J Mol Sci 2016;17:1415. DOI PubMed PMC 
28. Paiva R, Gomes I, Casimiro S, Fernandes I, Costa L. c-Met expression in renal cell carcinoma with bone metastases. J Bone Oncol 2020;25:100315. DOI PubMed PMC

29. Hass R, Jennek S, Yang Y, Friedrich K. c-Met expression and activity in urogenital cancers - novel aspects of signal transduction and medical implications. Cell Commun Signal 2017;15:10. DOI PubMed PMC

30. Birchmeier C, Birchmeier W, Gherardi E, Vande Woude GF. Met, metastasis, motility and more. Nat Rev Mol Cell Biol 2003;4:91525. DOI PubMed

31. Gibney GT, Aziz SA, Camp RL, et al. c-Met is a prognostic marker and potential therapeutic target in clear cell renal cell carcinoma. Ann Oncol 2013;24:343-9. DOI PubMed PMC

32. Mukai S, Yorita K, Kawagoe Y, et al. Matriptase and MET are prominently expressed at the site of bone metastasis in renal cell carcinoma: immunohistochemical analysis. Hum Cell 2015;28:44-50. DOI PubMed PMC

33. Aisen AM, Martel W, Braunstein EM, McMillin KI, Phillips WA, Kling TF. MRI and CT evaluation of primary bone and soft-tissue tumors. AJR Am J Roentgenol 1986;146:749-56. DOI PubMed

34. O'Sullivan GJ, Carty FL, Cronin CG. Imaging of bone metastasis: an update. World J Radiol 2015;7:202-11. DOI PubMed PMC

35. Hamaoka T, Madewell JE, Podoloff DA, Hortobagyi GN, Ueno NT. Bone imaging in metastatic breast cancer. J Clin Oncol 2004:22:2942-53. DOI PubMed

36. Rieden K. Conventional imaging and computerized tomography in diagnosis of skeletal metastases. Radiologe 1995;35:15-20. PubMed

37. Pathak AP. Magnetic resonance imaging of tumor physiology. Methods Mol Med 2006;124:279-97. DOI PubMed

38. Yang HL, Liu T, Wang XM, Xu Y, Deng SM. Diagnosis of bone metastases: a meta-analysis comparing 18FDG PET, CT, MRI and bone scintigraphy. Eur Radiol 2011;21:2604-17. DOI PubMed

39. Fogelman I, Cook G, Israel O, Van der Wall H. Positron emission tomography and bone metastases. Semin Nucl Med 2005;35:135-42. DOI PubMed

40. Wu HC, Yen RF, Shen YY, Kao CH, Lin CC, Lee CC. Comparing whole body 18F-2-deoxyglucose positron emission tomography and technetium-99m methylene diphosphate bone scan to detect bone metastases in patients with renal cell carcinomas - a preliminary report. J Cancer Res Clin Oncol 2002;128:503-6. DOI PubMed

41. Sohaib SA, Cook G, Allen SD, Hughes M, Eisen T, Gore M. Comparison of whole-body MRI and bone scintigraphy in the detection of bone metastases in renal cancer. Br J Radiol 2009;82:632-9. DOI PubMed

42. Coleman RE. Clinical features of metastatic bone disease and risk of skeletal morbidity. Clin Cancer Res 2006;12:6243s-9s. DOI PubMed

43. Roelofs AJ, Thompson K, Gordon S, Rogers MJ. Molecular mechanisms of action of bisphosphonates: current status. Clin Cancer Res 2006; 12:6222s-30s. DOI PubMed

44. Elomaa I, Blomqvist C, Porkka L, et al. Treatment of skeletal disease in breast cancer: a controlled clodronate trial. Bone 1987;8 Suppl 1:S53-6. PubMed

45. Paterson AH, Powles TJ, Kanis JA, McCloskey E, Hanson J, Ashley S. Double-blind controlled trial of oral clodronate in patients with bone metastases from breast cancer. J Clin Oncol 1993;11:59-65. DOI PubMed

46. Hortobagyi GN, Theriault RL, Porter L, et al. Efficacy of pamidronate in reducing skeletal complications in patients with breast cancer and lytic bone metastases. Protocol 19 Aredia Breast Cancer Study Group. N Engl J Med 1996;335:1785-91. DOI PubMed

47. Theriault RL, Lipton A, Hortobagyi GN, et al. Pamidronate reduces skeletal morbidity in women with advanced breast cancer and lytic bone lesions: a randomized, placebo-controlled trial. Protocol 18 Aredia Breast Cancer Study Group. J Clin Oncol 1999;17:846-54. DOI PubMed

48. Rosen LS, Gordon D, Kaminski M, et al. Zoledronic acid versus pamidronate in the treatment of skeletal metastases in patients with breast cancer or osteolytic lesions of multiple myeloma: a phase III, double-blind, comparative trial. Cancer J 2001;7:377-87. PubMed

49. Costa L. Which bisphosphonate to treat bone metastases? Lancet Oncol 2014;15:15-6. DOI PubMed

50. Rosen LS, Gordon D, Tchekmedyian S, et al. Zoledronic acid versus placebo in the treatment of skeletal metastases in patients with lung cancer and other solid tumors: a phase III, double-blind, randomized trial--the Zoledronic Acid Lung Cancer and Other Solid Tumors Study Group. J Clin Oncol 2003;21:3150-7. DOI PubMed

51. Broom RJ, Hinder V, Sharples K, et al. Everolimus and zoledronic acid in patients with renal cell carcinoma with bone metastases: a randomized first-line phase II trial. Clin Genitourin Cancer 2015;13:50-8. DOI PubMed

52. Lipton A, Fizazi K, Stopeck AT, et al. Superiority of denosumab to zoledronic acid for prevention of skeletal-related events: a combined analysis of 3 pivotal, randomised, phase 3 trials. Eur J Cancer 2012;48:3082-309. DOI PubMed

53. Lacey DL, Boyle WJ, Simonet WS, et al. Bench to bedside: elucidation of the OPG-RANK-RANKL pathway and the development of denosumab. Nat Rev Drug Discov 2012;11:401-19. DOI PubMed

54. Henry DH, Costa L, Goldwasser F, et al. Randomized, double-blind study of denosumab versus zoledronic acid in the treatment of bone metastases in patients with advanced cancer (excluding breast and prostate cancer) or multiple myeloma. J Clin Oncol 2011;29:1125-32. DOI PubMed

55. Motzer RJ, Hutson TE, Cella D, et al. Pazopanib versus sunitinib in metastatic renal-cell carcinoma. N Engl J Med 2013;369:722-31. DOI PubMed

56. Costa L, Fizazi K, Saad F, et al. Denosumab and zoledronic acid treatment in patients with genitourinary cancers and bone metastases. JCO 2013;31:5079-5079. DOI

57. Stopeck AT, Fizazi K, Body JJ, et al. Safety of long-term denosumab therapy: results from the open label extension phase of two phase 3 studies in patients with metastatic breast and prostate cancer. Support Care Cancer 2016;24:447-55. DOI PubMed PMC 
58. Guillot A, Joly C, Barthélémy P, et al. Denosumab toxicity when combined with anti-angiogenic therapies on patients with metastatic renal cell carcinoma: a GETUG study. Clin Genitourin Cancer 2019;17:e38-43. DOI PubMed

59. Fusco V, Porta C, Saia G, et al. Osteonecrosis of the jaw in patients with metastatic renal cell cancer treated with bisphosphonates and targeted agents: results of an italian multicenter study and review of the literature. Clin Genitourin Cancer 2015;13:287-94. DOI PubMed

60. McKay RR, Bossé D, Gray KP, et al. Radium-223 dichloride in combination with vascular endothelial growth factor-targeting therapy in advanced renal cell carcinoma with bone metastases. Clin Cancer Res 2018;24:4081-8. DOI PubMed PMC

61. Beisland C, Johannesen TB, Klepp O, et al. Overall survival in renal cell carcinoma after introduction of targeted therapies: a Norwegian population-based study. Onco Targets Ther 2017;10:371-85. DOI PubMed PMC

62. Chang AJ, Zhao L, Zhu Z, et al. The past, present and future of immunotherapy for metastatic renal cell carcinoma. Anticancer Res 2019;39:2683-7. DOI PubMed

63. Schultze-Seemann W, Schulz H, Tschechne B, Häckl M. Bevacizumab plus IFN-alpha-2a in first-line treatment of patients with advanced or metastatic renal cell carcinoma: a prospective German non-interventional study. Anticancer Res 2019;39:875-82. DOI PubMed

64. Maita, S. et al. Antitumor effect of sunitinib against skeletal metastatic renal cell carcinoma through inhibition of osteoclast function. Int J Cancer 2012;130:677-84. DOI PubMed

65. Kalra S, Verma J, Atkinson BJ, et al. Outcomes of patients with metastatic renal cell carcinoma and bone metastases in the targeted therapy era. Clin Genitourin Cancer 2017;15:363-70. DOI PubMed

66. Zołnierek J, Nurzyński P, Langiewicz P, et al. Efficacy of targeted therapy in patients with renal cell carcinoma with pre-existing or new bone metastases. J Cancer Res Clin Oncol 2010;136:371-78. DOI PubMed

67. Choueiri TK, Escudier B, Powles T, et al; METEOR Investigators. Cabozantinib versus Everolimus in Advanced Renal-Cell Carcinoma. N Engl J Med 2015;373:1814-23. DOI PubMed PMC

68. Escudier B, Powles T, Motzer RJ, et al. Cabozantinib, a New Standard of care for patients with advanced renal cell carcinoma and bone metastases? J Clin Oncol 2018;36:765-72. DOI PubMed PMC

69. Motzer RJ, Escudier B, McDermott DF, et al; CheckMate 025 Investigators. Nivolumab versus everolimus in advanced renal-cell carcinoma. N Engl J Med 2015;373:1803-13. DOI PubMed PMC

70. Fioramonti M, Santini D, Iuliani M, et al. Cabozantinib targets bone microenvironment modulating human osteoclast and osteoblast functions. Oncotarget 2017;8:20113-21. DOI PubMed PMC

71. Escudier B, Sharma P, McDermott DF, et al; CheckMate 025 investigators. CheckMate 025 randomized phase 3 study: outcomes by key baseline factors and prior therapy for nivolumab versus everolimus in advanced renal cell carcinoma. Eur Urol 2017;72:962-71. DOI PubMed

72. Australian and New Zealand Urogenital and Prostate Cancer Trials Group. Denosumab and pembrolizumab in clear cell renal carcinoma: a Phase II Trial (ANZUP 1601). Available from: https://clinicaltrials.gov/ct2/show/NCT03280667 [Last accessed on 6 Jul 2021].

73. Motzer RJ, Jonasch E, Michaelson MD, et al. NCCN guidelines insights: kidney cancer, version 2.2020. J Natl Compr Canc Netw 2019;17:1278-85. DOI PubMed

74. Zelefsky MJ, Greco C, Motzer R, et al. Tumor control outcomes after hypofractionated and single-dose stereotactic image-guided intensity-modulated radiotherapy for extracranial metastases from renal cell carcinoma. Int J Radiat Oncol Biol Phys 2012;82:1744-8. DOI PubMed PMC

75. Jhaveri PM, Teh BS, Paulino AC, et al. A dose-response relationship for time to bone pain resolution after stereotactic body radiotherapy (SBRT) for renal cell carcinoma (RCC) bony metastases. Acta Oncol 2012;51:584-8. DOI PubMed

76. Wang XS, Rhines LD, Shiu AS, et al. Stereotactic body radiation therapy for management of spinal metastases in patients without spinal cord compression: a phase 1-2 trial. Lancet Oncol 2012;13:395-402. DOI PubMed PMC

77. Dabestani S, Marconi L, Hofmann F, et al. Local treatments for metastases of renal cell carcinoma: a systematic review. Lancet Oncol 2014;15:e549-61. DOI PubMed

78. Du Y, Pahernik S, Hadaschik B, et al. Survival and prognostic factors of patients with renal cell cancer with bone metastasis in the era of targeted therapy: a single-institution analysis. Urol Oncol 2016;34:433.e1-8. DOI PubMed

79. Kato S, Murakami H, Demura S, et al. Spinal metastasectomy of renal cell carcinoma: a 16-year single center experience with a minimum 3-year follow-up. J Surg Oncol 2016;113:587-92. DOI PubMed

80. Hunter GK, Balagamwala EH, Koyfman SA, et al. The efficacy of external beam radiotherapy and stereotactic body radiotherapy for painful spinal metastases from renal cell carcinoma. Pract Radiat Oncol 2012;2:e95-e100. DOI PubMed

81. Teyssonneau D, Gross-Goupil M, Domblides C, et al. Treatment of spinal metastases in renal cell carcinoma: a critical review. Crit Rev Oncol Hematol 2018;125:19-29. DOI PubMed 